\title{
OR-IASIOH
}

Available online at Website http://ejournal.undip.ac.id/index.php/rotasi

\section{THE AERODYNAMICS ANALYSIS OF AIRFOILS FOR HORIZONTAL AXIS WIND TURBINE BLADE USING COMPUTATIONAL FLUID DYNAMIC}

\author{
*Abdulhafiz Younis Mokhetar, Eflita Yohana, MSK. Tony Suryo Utomo \\ Mechanical Engineering Department, Faculty of Engineering, Diponegoro University \\ Jl. Prof. Soedharto SH Tembalang Semarang 50275 \\ *E-mail: hafeed778@yahoo.com
}

\begin{abstract}
This paper included in designing and simulating for 2D. It may use two software's called Gambit and FLUENT to generate the data from the fluid flow cases. In this research select two models NACA airfoil NACA4412 and NACA4415. Chose NACA 4412 because lift coefficient is higher than NACA4415. In this study computational flow over an airfoil at different angles of attack $\left(0^{\circ}, 5^{\circ}, 10^{\circ}, 15^{\circ}, 20^{\circ}\right)$ using CFD (Computational fluid dynamics) simulation two dimensional airfoil NACA 4412 and NACA4415 CFD models are presented using ANSYS-FLUENT software. For this model Using turbulent viscosity k-epsilon (standard wall function) near the wall and wind velocity $5 \mathrm{~m} / \mathrm{s}$ Here, NACA 4412 airfoil profile is considered for analysis of wind turbine blade. Geometry of airfoil is created using GAMBIT 2.4.6 and CFD analysis is carried out using FLUENT 6.3.26 at various angles of attack from $0^{\circ}$ to $20^{\circ}$. Lift and Drag forces along with the angle of attack are the important parameters in a wind turbine system. The Lift and Drag forces are calculated at different sections for angle of attack from $0^{\circ}$ to $20^{\circ}$ for low Reynolds number. The analysis showed that the angle of attack of $10^{\circ}$ has high Lift/Drag ratio. The airfoil NACA 4412 is analyzed based on computational fluid dynamics to identify its suitability for its application and good agreement is made between the results.
\end{abstract}

Key words: CFD simulation, airfoil, angle of attack.

\section{NOMENCLATURE}

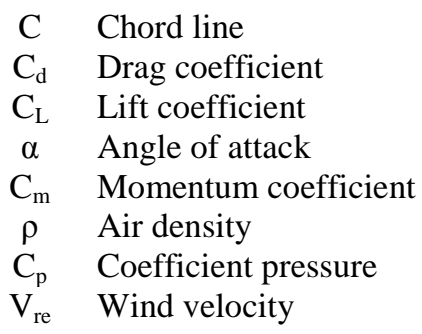

\section{INTRODUCTION}

The design for a model of airfoil such as NACA 4412 and NACA 4415 demanded knowledge aerodynamic properties. It was built by using gambit code, chosen and specified clustering the mesh generation with boundary conditions [1]. An airfoil is defined as the cross section of a body that is placed in an airstream in order to produce a useful aerodynamic force in the most efficient manner possible [2]. A physical flow phenomenon for air passing through a streamlined body show that the viscous effect is limited to the flow region near the body surface [3]. The performance of aerodynamic at the upper surface of the airfoil will be limited on turbulent boundary layer separation, the aerodynamic properties of naca 4412 airfoil section have been investigated in a number of previous studies, such as Badran and Bruun [4]. Badran, kayiem and. Nakayama also woodcock [5]. There are two- equation turbulence models are tested for the ability to predict boundary layer separation on naca 4412 airfoil at different position of angle of attack. The two equation model is k-epsilon. The most detailed data in the separated flow region over airfoils were measured by seetharam and Wentz [6]. Aim this research the aerodynamic analysis of airfoils for horizontal axis wind turbine blade using computational fluid dynamic cfd method of analysis.

\section{METHODOLOGY}

The methodology of this research can be easily described through Flowchart that consists of certain steps involved to finish the research. This Flowchart as in Figure 1 shows the flow of the process of analyzing and simulation 2D airfoil with all method used in this research. 
Abdulhafiz Younis Mokhetar dkk., The Aerodynamics Analysis Of Airfoils For Horizontal Axis Wind Turbine Blade Using Computational Fluid Dynamic

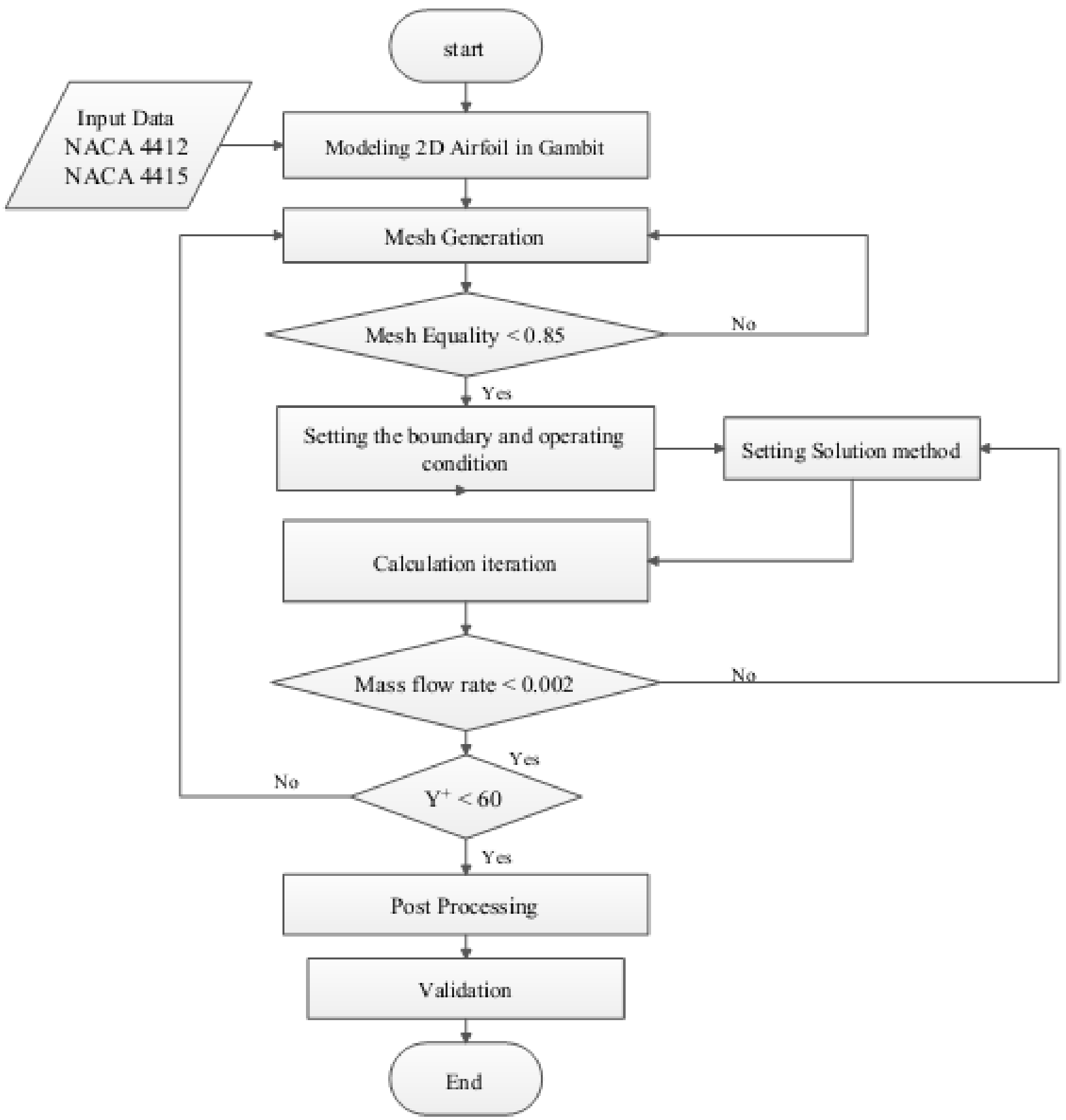

Figure 1. Flowchart of the methodology.

The 2D models of airfoil NACA 4412 and NACA 4415 were created by gambit. Input coordinates for certain points created from software Design foil workshop DEMO.
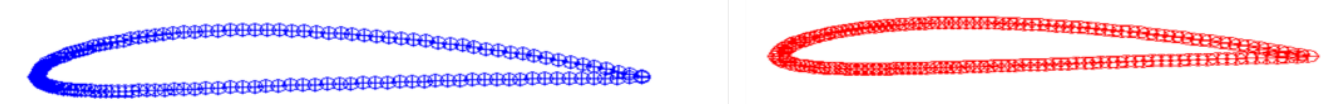

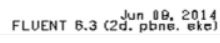

(a)

Figure2. a) NACA airfoil 4412 and b) NACA airfoil 4415 
Characteristics of these airfoils from digit 4 it has same location of the maximum camber in tenths of chord measured from LE(40). But difference maximum thickness, after create this airfoil and analysis chosen one for best performance.

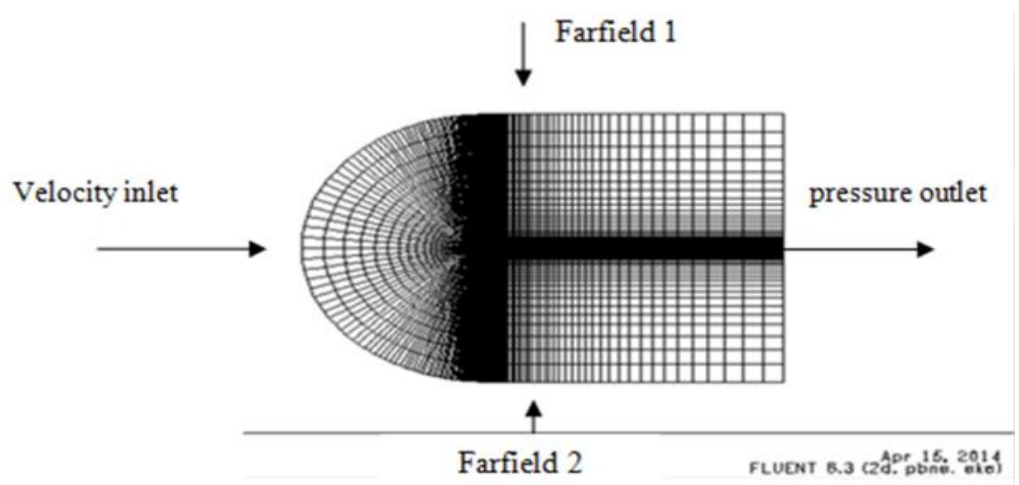

Figure 3. Topology of computational mesh

Figure 3 shows the type of mesh used in this research was hexahedral. Skewness equality of this mesh was less than 0.85 . The total elements of mesh equal to 12270 . The simulation of $2 \mathrm{D}$ airfoil in this research was created by using $\mathrm{k}-\varepsilon$ turbulent model in Fluent. Table1 gives the complete computational parameter that's used in this simulation.

Table1. Computational conditions of 2D-dimensional simulation.

\begin{tabular}{cll}
\hline No. & Solver & Pressure based steady state \\
\hline 1. & Fluid Material & Air \\
2. & Density $\left(\mathrm{kg} / \mathrm{m}^{3}\right)$ & 1.225 \\
3. & Viscosity $(\mathrm{kg} / \mathrm{m}-\mathrm{s})$ & 1.7894 \\
4. & Pressure & $101325 \mathrm{pa}$ \\
5. & Inlet velocity & $5 \mathrm{~m} / \mathrm{s}$ \\
6. & Pressure velocity coupling & SIMPLE \\
7. & Momentum & Second order upwind \\
8. & Boundary condition & Velocity inlet, pressure outlet. \\
\hline
\end{tabular}

\section{RESULTS AND DISCUSSION}

Figure 4 until Figure 8 shows the contours of pressure and velocity magnitude of the NACA 4412 airfoil, there is a region of high pressure at the leading edge (stagnation point) and region of low pressure on the upper surface of the airfoil. From these Figures it can be seen that velocity at the upper region has the higher magnitude, also at bottom region has lower magnitude.
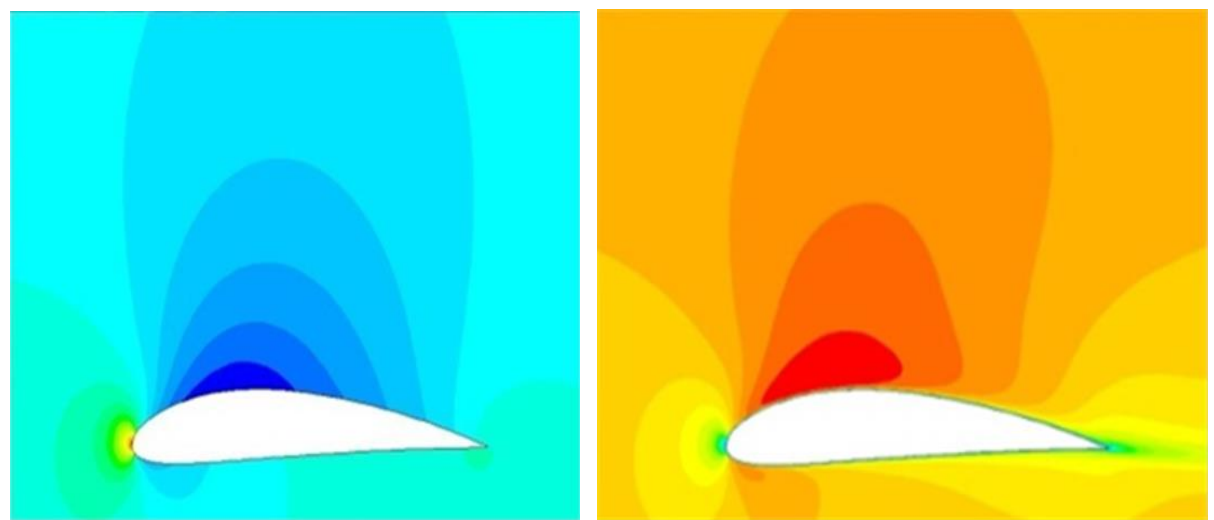

Figure 4. Static pressure and velocity at $0^{\circ}$ Angle of attack. 

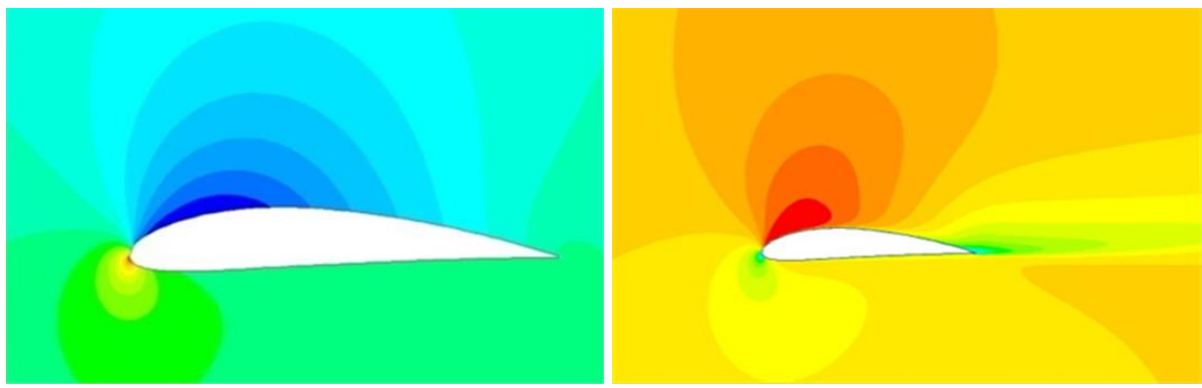

Figure 5. Static pressure and velocity at $5^{\circ}$ Angle of attack

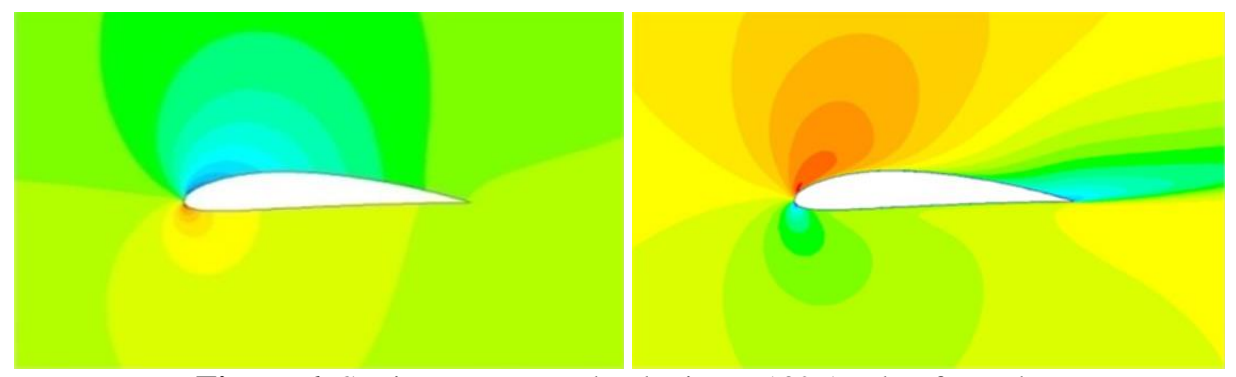

Figure 6. Static pressure and velocity at $10^{\circ}$ Angle of attack.

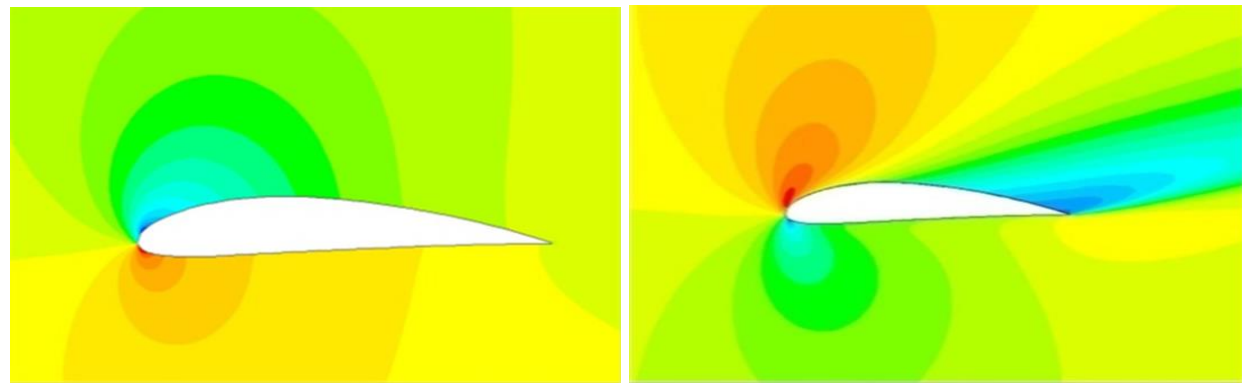

Figure 7. Static pressure and velocity at $15^{\circ}$ Angle of attack.

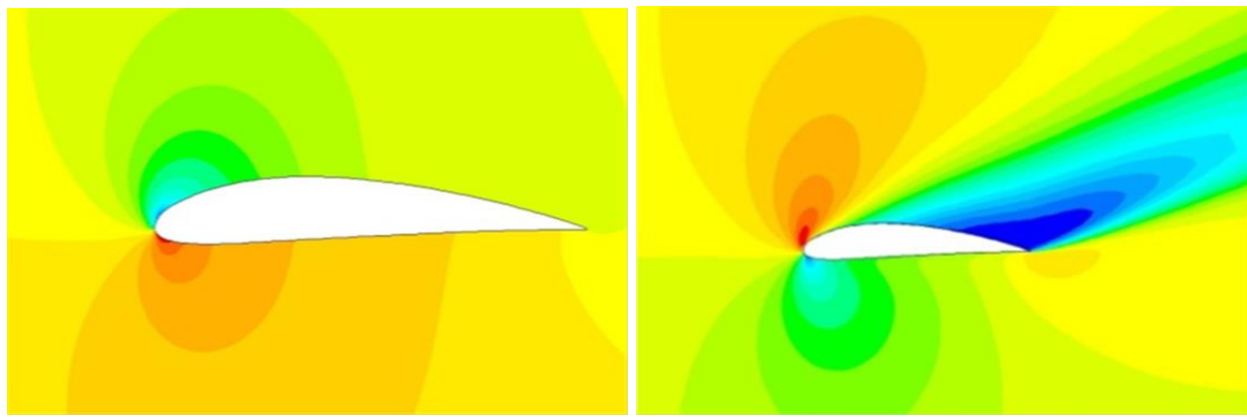

Figure 8. Static pressure and velocity at $20^{\circ}$ Angle of attack.

The values of $C_{L}$ and $C_{D}$ were found out for various angles of attack. The Lift and Drag forces are calculated for the angle of attack at $(0,5,10,15,20)$ degree. For the velocity constant $5 \mathrm{~m} / \mathrm{sec}$. The lift, drag, momentum for different angle of attack is shown in Table 2.

Table 2. Shows lift and drag and momentum coefficient of NACA4412 for various angles of attack

\begin{tabular}{cccc}
\hline AOA & $\mathrm{C}_{\mathrm{L}}$ & $\mathrm{C}_{\mathrm{d}}$ & $\mathrm{C}_{\mathrm{m}}$ \\
\hline 0 & 0.41134 & 0.057367 & 0.2064 \\
5 & 0.84674 & 0.080448 & 0.31248 \\
10 & 1.1905 & 0.1398 & 0.39019 \\
15 & 1.3638 & 0.22549 & 0.42291 \\
20 & 1.3572 & 0.32823 & 0.43024 \\
\hline
\end{tabular}


Figure 9 until Figure 13 shows the contours of velocity and pressure of the NACA 4415 airfoil, there is a region of high pressure at the leading edge (stagnation point) and region of low pressure on the upper surface of the airfoil. From these Figures it can be seen that the velocity in the upper region has the highest magnitude, also at a bottom region has lower magnitude.

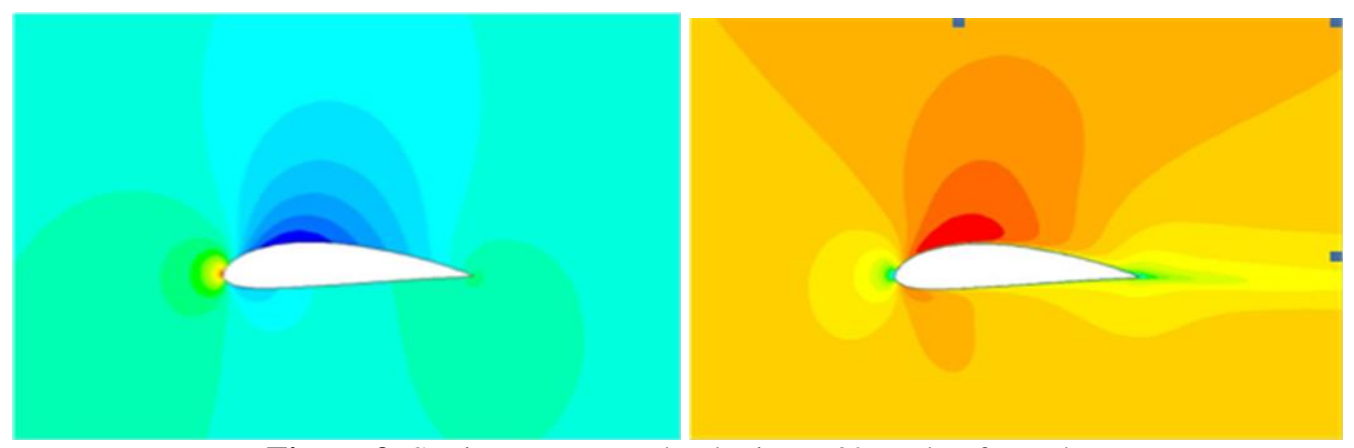

Figure 9. Static pressure and velocity at $0^{\circ}$ angle of attack.

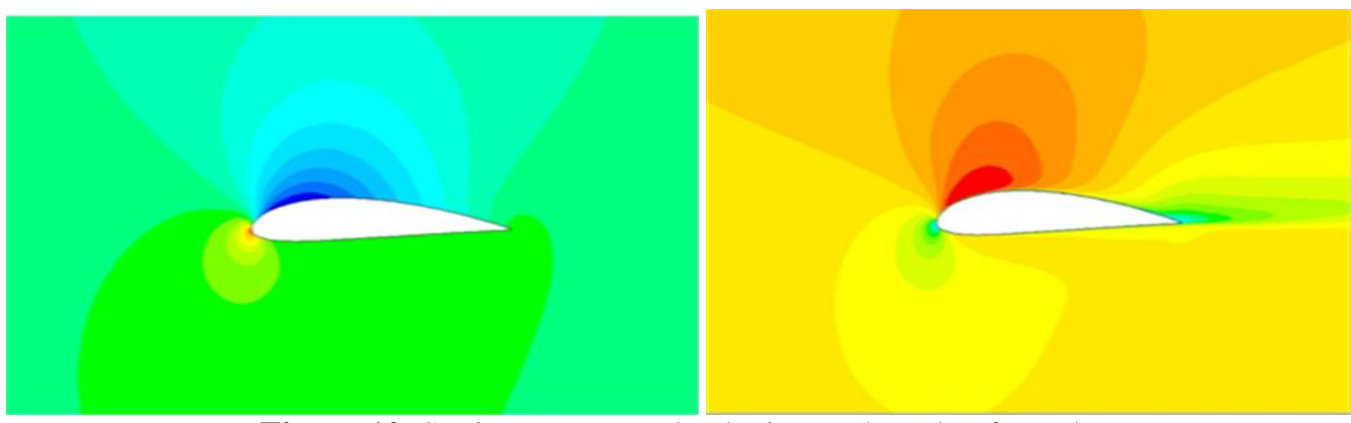

Figure 10. Static pressure and velocity at $5^{\circ}$ angle of attack.

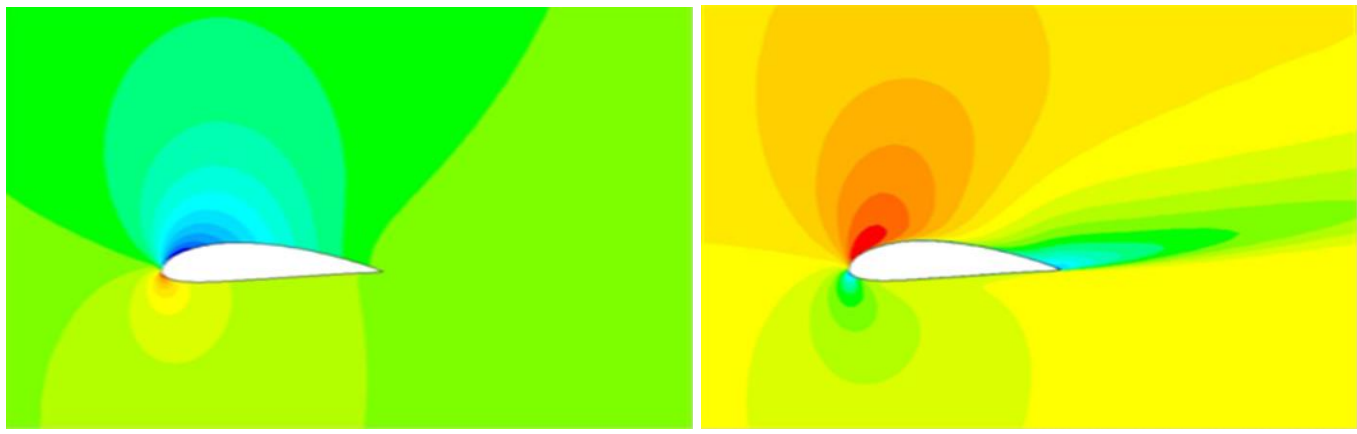

Figure 11. Static pressure and velocity at $10^{\circ}$ angle of attack.
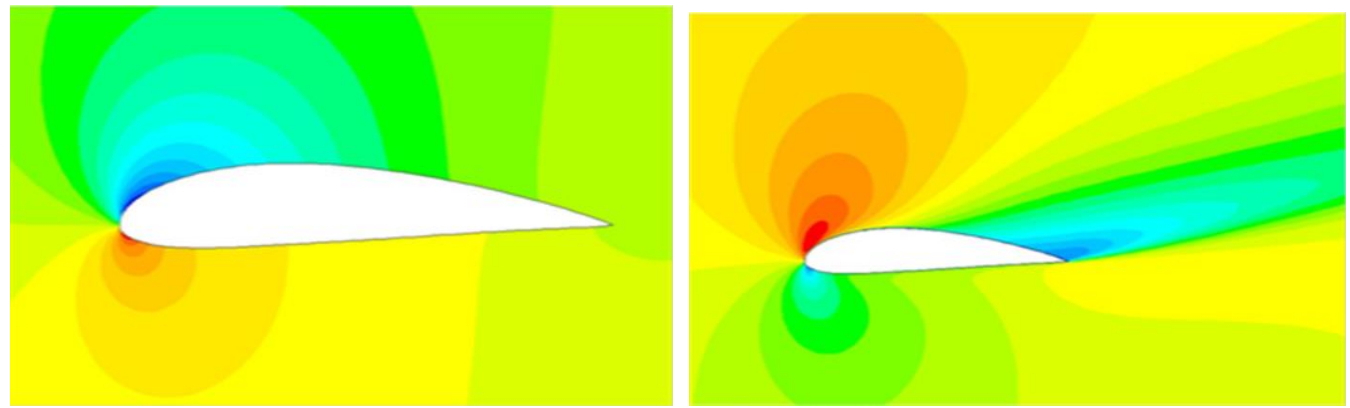

Figure 12 . Static pressure and velocity at $15^{\circ}$ angle of attack. 


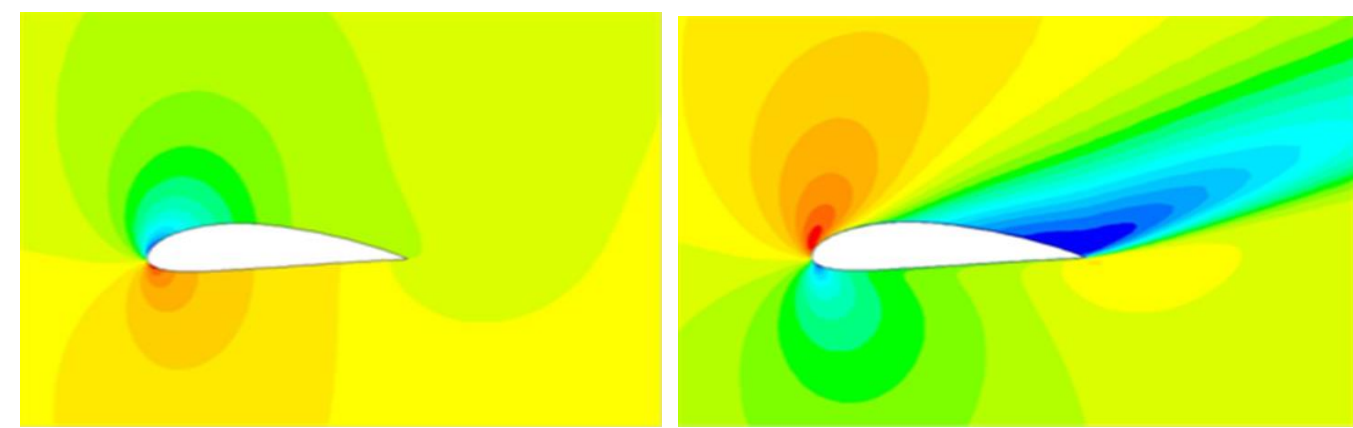

Figure 13. Static pressure and velocity at $20^{\circ}$ angle of attack.

The values of $C_{L}$ and $C_{d}$ were found out for various angles of attack. The lift and drag forces are calculated from the angle of attack at $(0,5,10,15,20)$ degree. For the velocity constant $5 \mathrm{~m} / \mathrm{Sec}$. The lift, drag, momentum for different angles of attack is shown in Table 3.

Table 3. Shows lift and drag and momentum coefficient of NACA4415 for various angles of attack

\begin{tabular}{cccc} 
AOA & CL & $\mathrm{Cd}$ & $\mathrm{Cm}$ \\
\hline 0 & 0.3816 & 0.0663 & 0.1905 \\
5 & 0.7988 & 0.0862 & 0.2886 \\
10 & 1.1409 & 0.1380 & 0.3645 \\
15 & 1.3475 & 0.2142 & 0.4058 \\
20 & 1.3829 & 0.3051 & 0.4149 \\
\hline
\end{tabular}

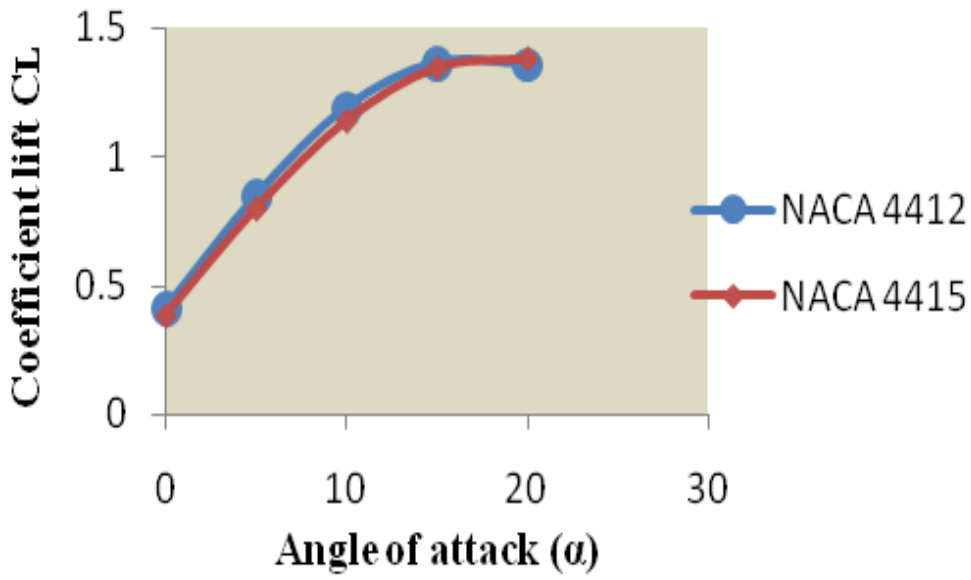

Figure 14. Numerical lift and angle of attack curve in comparison with airfoils wind turbine.

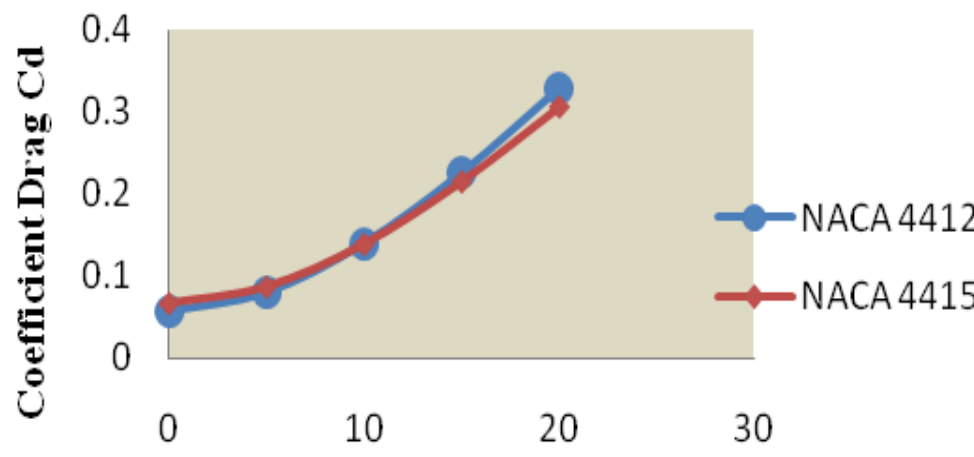

Angle of attack $(\alpha)$

Figure 15. Numerical drag and angle of attack curve in comparison with airfoils wind turbine. 


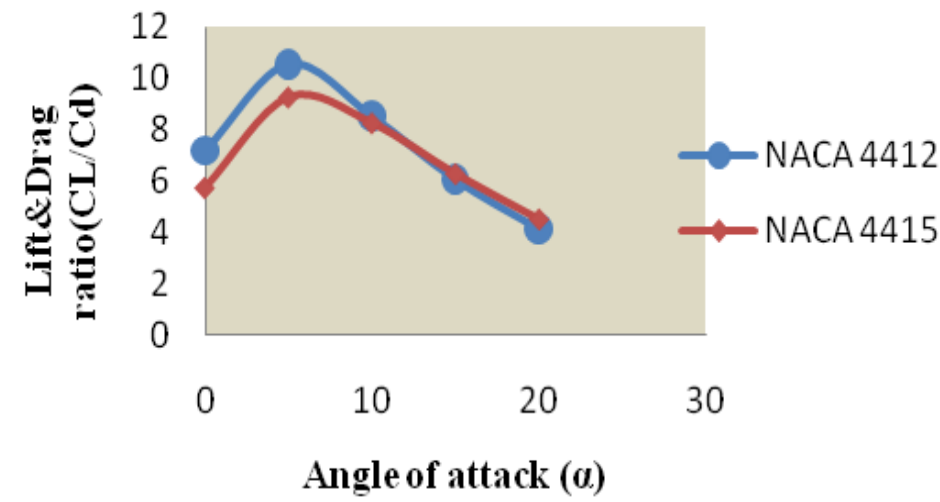

Figure 16. Numerical lift and Drag ratio and angle of attack curve in comparison with airfoil of wind turbine.

Lift coefficient keeps growing until it reaches to the critical angle of attack. The critical angles of attack are $15^{\circ}$ For both airfoil NACA 4412 and the NACA 4415 airfoil. As shown in Figure 14 it is obvious that NACA4412 airfoil always has a higher lift coefficient and lower drag coefficient than NACA4415 under the same AoA as lift and drag coefficient ratio for NACA4412 airfoil is higher than NACA4415 airfoil shown in Figure 16. The coefficient of lift and drag is calculated for this NACA 4412 series for the angle of attack $0^{\circ}$ to $20^{\circ}$. The coefficient of lift increases with increase in angle of attack up to $15^{\circ}$. After $15^{\circ}$, the coefficient of lift decreases and stall occurs at this angle of attack.

\section{VALIDATION OF SIMULATION RESULTS BY CFD}

Table 4. Shows of comparison of CL between simulation and CL Research -Gaurav Saxena

\begin{tabular}{ccccc}
\hline No. & $\alpha$ & $\begin{array}{c}\mathrm{C}_{\mathrm{L}} \\
\text { (Simulation) }\end{array}$ & $\begin{array}{c}\mathrm{C}_{\mathrm{L}} \text { (Journal-Gaurav } \\
\text { Saxena) }\end{array}$ & Error\% \\
\hline 1. & 10 & 1.22 & 1.24 & $1.6 \%$ \\
2. & 12.5 & 1.31 & 1.4 & $6 \%$ \\
3. & 15 & 1.35 & 1.45 & $6.8 \%$ \\
4. & 16 & 1.34 & 1.54 & $12 \%$ \\
5. & 17 & 1.33 & 1.53 & $12.9 \%$ \\
6. & 17.5 & 1.32 & 1.51 & $12.5 \%$ \\
7. & 20 & 1.27 & 1.48 & $14 \%$ \\
8. & 22.5 & 1.20 & 1.40 & $16 \%$ \\
\hline
\end{tabular}

Table 4 shows the comparison of $\mathrm{C}_{\mathrm{L}}$ between the simulation results and the research (Gaurav Saxena ), at same wind velocity $18.4 \mathrm{~m} / \mathrm{s}$. There is agreement between simulation result and the paper with Percentage of max $16 \%$.

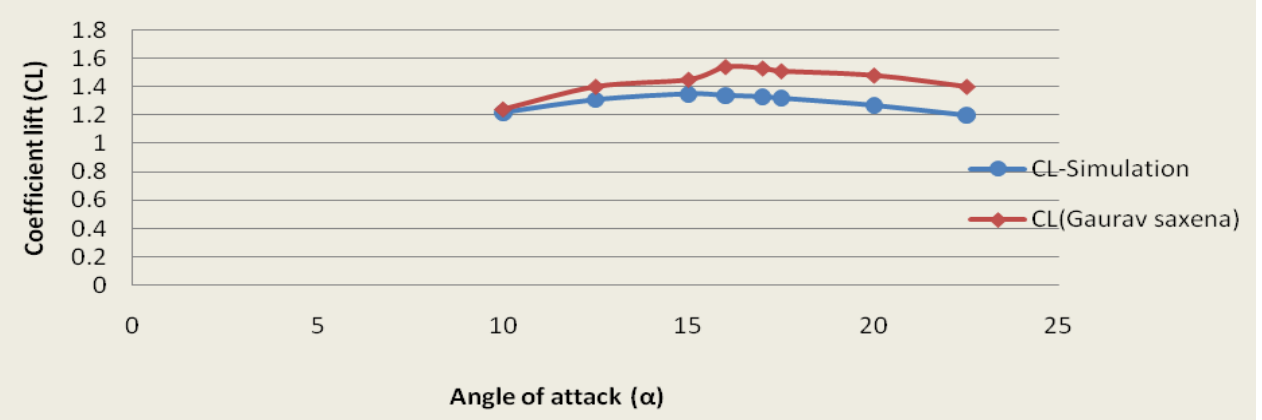

Figure 17. The resultant graph between $C_{1}$ and angle of attack (Simulation and research- Gaurav Saxena) [7].

Figure 17 shows a comparison of lift predictions with research (Gaurav Saxena). Agreement is good at low angles of attack, where the flow is fully attached, the agreement deteriorates as the angle of attack increases, and viscous effects start to show up as a reduction in lift with increasing angle of attack, until, finally, the airfoil stalls. 


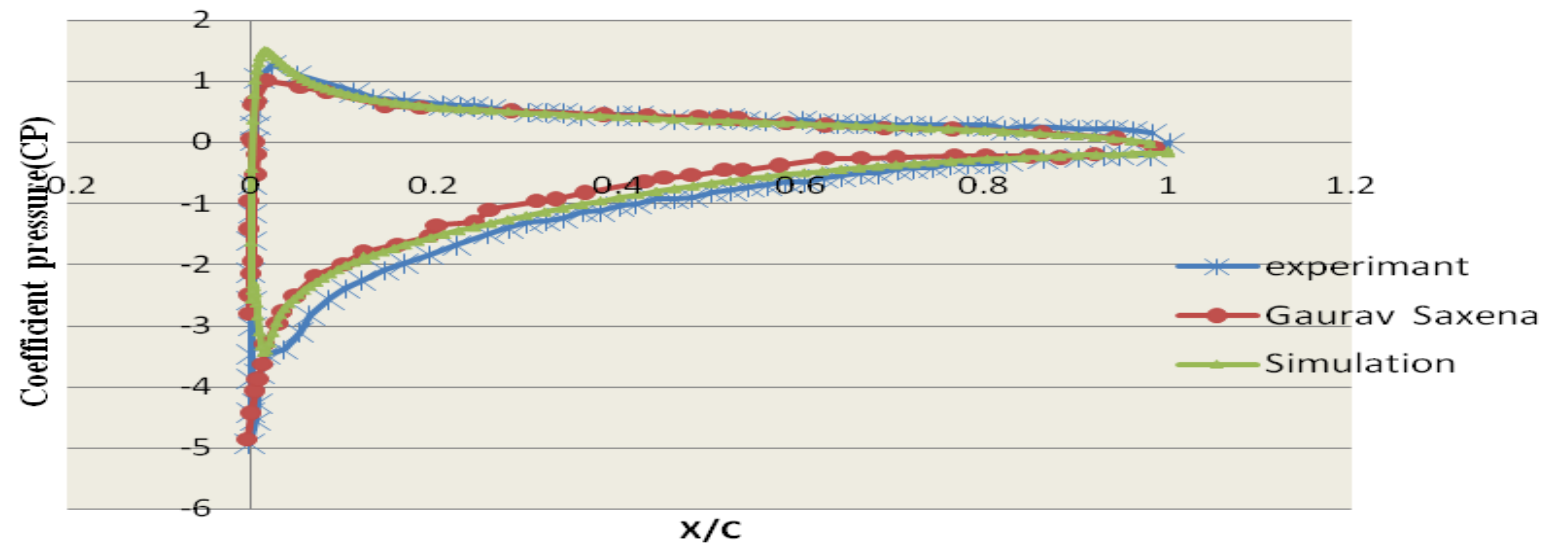

Figure 18. Resultant graph between $C_{p}$ and $X / C$

Figure 18 shows the relation between coefficient pressure $\mathrm{C}_{\mathrm{p}}$ and $\mathrm{X} / \mathrm{C}$. This is clear that simulation results at $10^{\circ}$ angle of attack are matched with research (Gaurav Saxena), results in this research validation is completed [8].

\section{CONCLUSIONS}

This paper showed the behavior of the 4-digit symmetric airfoil NACA 4412 and NACA 4415 at various angles of attack. The most appropriate turbulence model for these simulations was using the k-epsilon turbulent viscosity model, which had a good agreement with the validation of research (Gaurav Saxena) after investigation of a wider range of angles of attack. The coefficient of Lift and drag is calculated for this NACA 4412,NACA 4415 series for the angle of attack $0^{\circ}$ to $20^{\circ}$. The coefficient of Lift/Drag ratio increases with increase in angle of attack up to $15^{\circ}$. After $15^{\circ}$, Lift/Drag ratio decreases with increase in Angle of attack. The coefficient of pressure is analyzed in the upper and lower surface of the airfoil for the angle of attack varies from $0^{\circ}$ to $20^{\circ}$. The results showed that the upper surface has a lower negative coefficient of pressure at a higher angle of attack and lower surface has a lower negative coefficient of pressure at lower angle of attack. The curves of the lift and the drag coefficient are shown from various angles of attack, computed with lift coefficient for this research and compared with research (Gaurav Saxena). This is clear that simulation results at angle of attack are matched with research (Gaurav Saxena). So validation of results is completed.

\section{REFERENCES}

[1] A. Abud AL, N. Abass, Affairs Contracts Department The University of Mustansiriya CFD assessment to Subsonic flow around NACA4412, Vol. 15, No.4, Des 2011 ISSN 1813- 7822

[2] M. kevadiya, A. Vaidya, (2013), Department of Mechanical Engineering, Government College of engineering,Valsad,Gujarat,India1,AssistantProfessor,Gujarat,.2,Issue5,May2013Copyrightto ijirset 1686, 2d analysis of NACA 4412 airfoil.

[3] B. Basuno, Z. Abdullah, (2001),Computational aerodynamic analysis of multicomponent airfoil using viscous-in viscid interaction scheme, Science, University of Malaysia.37(2001)365-380.

[4] O. Badran, H . Bruun, (2003), Turbulent flow over a NACA 4412 airfoil at angle of attack 15 degree, Proceedings of FEDSM'03, 4th ASME_JSME Joint Fluids Engineering Conference, Honolulu, Hawaii, USA, July 6-11.

[5] D. Adair, (1987), Characteristics of a trailing flap flow with small separation, Experiments in Fluids 5, 114128.

[6] D. Coles, A. Wadcock, (1979), Flying-hot-wire study of flow past an NACA 4412 airfoil at maximum lift. AIAA 17:4, 321-329.

[7] M. Agrawal, G .Saxena. (2013). Analysis of wings using Airfoil NACA4412 at different angle of attack , Department of mechanical engineering, RGPV University, India, Vol.3,1ssue.3,May. June.2013pp-1467-1469.

[8] G. Saxena ,M. agrawal.(2013). Aerodynamic analysis of NACA 4412 airfoil using CFD Issue3,Vol.4. 